\title{
Spatiotemporal epidemiology of COVID-19 from an epidemic course perspective
}

\author{
Yuling Huang, ${ }^{1}$ Shujuan Yang, ${ }^{2,3}$ Yuxuan Zou, ${ }^{3}$ Jianming Su, ${ }^{4}$ Canglang Wu, ${ }^{5}$ Bo Zhong, \\ Peng Jia ${ }^{3,6}$ \\ ${ }^{1}$ Sichuan Centre for Disease Control and Prevention, Chengdu; ${ }^{2}$ West China School of Public Health and \\ West China Fourth Hospital, Sichuan University, Chengdu; ${ }^{3}$ International Institute of Spatial Lifecourse \\ Epidemiology (ISLE), Wuhan University, Wuhan; ${ }^{4}$ Health Commission of Sichuan Province, Chengdu; \\ ${ }^{5}$ Health Information Centre of Sichuan Province, Chengdu; ${ }^{6}$ School of Resource and Environmental \\ Sciences, Wuhan University, Wuhan, China
}

\begin{abstract}
Although coronavirus disease 2019 (COVID-19) remains rampant in many countries, it has recently waned in Sichuan, China. This study examined spatiotemporal variations of the epidemiological characteristics of COVID-19 across its course. Three approaches, i.e. calendar-based, measure-driven and data-driven ones, were applied to all individual cases reported as of $30^{\text {th }}$ November 2020, dividing the COVID-19 pandemic into five periods. A total of 808 people with confirmed diagnosis and 279 asymptomatic cases were reported, the majority of whom were aged 30-49 and $<30$ years, respectively. The highest risk was seen in Chengdu (capital city), with 411 confirmed and 195 asymptomatic cases. The main sources of infection changed from importation from Hubei Province to importation from other provinces,
\end{abstract}

Correspondence: Peng Jia, School of Resource and Environmental Sciences, Wuhan University, Wuhan, China.

E-mail: jiapengff@hotmail.com

Bo Zhong, Sichuan Center for Disease Control and Prevention, Chengdu, China. E-mail: zhongbo1968@163.com

Key words: COVID-19; epidemiology; spatiotemporal analysis; spatial analysis; epidemic; epidemic course; health geography; China.

Acknowledgements: this study was supported by the Zhejiang University Special Scientific Research Fund for COVID-19 Prevention and Control (2020XGZX057), the Special Funds for Prevention and Control of COVID-19 of Sichuan University (2020scunCoV10010), and the International Institute of Spatial Lifecourse Epidemiology (ISLE).

Contributions: YH and SY contributed equally.

Received for publication: 11 June 2021.

Revision received: 14 August 2021.

Accepted for publication: 16 August 2021.

(C) Copyright: the Author(s), 2022

Licensee PAGEPress, Italy

Geospatial Health 2022; 17(s1):1023

doi:10.4081/gh.2022.1023

This article is distributed under the terms of the Creative Commons Attribution Noncommercial License (CC BY-NC 4.0) which permits any noncommercial use, distribution, and reproduction in any medium, provided the original author(s) and source are credited. then local transmission and ultimately importation from foreign countries. The periods highlighted by the three methods presented different epidemic patterns and trends. The calendar-based periods were even with most cases aggregated in the first period, which did not reflect various transmission patterns of COVID-19 due to various sources of infection; the measure-driven and data-driven periods were not consistent with each other, revealing that the effects of implementing prevention measures were reflected on the epidemic trend with a time lag. For example, the decreasing trends of new cases occurred 7, 3 and 4 days later than the firstlevel emergency response, the district-level prevention measures and the second-level emergency response, respectively. This study has advanced our understanding of epidemic course and foreshown all stages of COVID-19 epidemic. Many countries can learn from our findings about what will occur next in their timelines and how to be better prepared.

\section{Introduction}

According to the Centres for Disease Control and Prevention (CDC) in the U.S., the coronavirus disease 2019 (COVID-19) is a highly contagious, viral disease that mainly spreads through respiratory droplets between people who are in close contact with one another (CDC, 2020). Since the onset of the outbreak in early January 2020, the epidemic trend in China has gradually transformed from local infections to infections by cases arriving from foreign countries. On $11^{\text {th }}$ March 2020, the World Health Organization declared COVID-19 a pandemic and on $30^{\text {th }}$ November 2020, the global number of COVID-19 infections had reached 61.8 million, including more than 1.4 million deaths (WHO, 2020). However, in China transmission of the infection started to slow down after the first outbreak in Hubei Province, and only a few new confirmed cases were detected after February 2020. Still, as of $30^{\text {th }}$ November 2020, a total of 93,329 confirmed COVID-19 cases had been detected across 34 provinces and special regions in China, resulting in 4750 deaths (WHO, 2020).

Compared to snapshots on the ground and numerical and textual results from non-spatial analyses, spatial epidemiological research can provide an overview of the geographic distribution and variations of health outcomes from a unique perspective, which would be more informative for targeting limited resources to the areas of the greatest need. Moreover, spatial epidemiological analyses on the basis of individual cases with detailed epi- 
demiological information can provide further insights for implementing fine-scale prevention measures that would be useful for local health sectors. Such spatial epidemiological studies of COVID-19 with respect to variations of infection source and potential individual risk factors have been lacking, although a handful geographic studies examined spatial clustering patterns of COVID-19 incidence (Li et al., 2020; Yang et al., 2020). An isolation between epidemiology and geography may underlie the lack of spatial epidemiological analyses based on individual epidemiological data (Jia and Yang, 2020a).

To be better prepared for decision-making for future epidemics, a comprehensive understanding of characteristics of COVID-19 transmission at different stages over the whole epidemic course is needed (Jia, 2020). The epidemic course of COVID-19 has been recognized as giving a useful overview that could assist our understanding of the dynamic characteristics over its epidemic cycle (Lipsitch et al., 2020). However, no studies have examined the COVID-19 from this perspective. Our study aimed to understand the epidemic course on the basis of a provincial dataset of true COVID-19 cases over the epidemic cycle. Taking one step further, we used three approaches, i.e. a calendar-based, a measuredriven and a data-driven one, to divide the course of the disease into different periods and investigate spatiotemporal variations of epidemiological characteristics of COVID-19 infection across periods, which would advance our understanding of spatial life course of the epidemic (Jia et al., 2020). Our fine-scale findings would also guide local health sectors to be better prepared for the next wave of COVID-19 or other future epidemics. More importantly, given that COVID-19 has waned in China, many countries in which COVID-19 remains rampant can learn from our results how to deal with the pandemic from a spatiotemporal perspective.
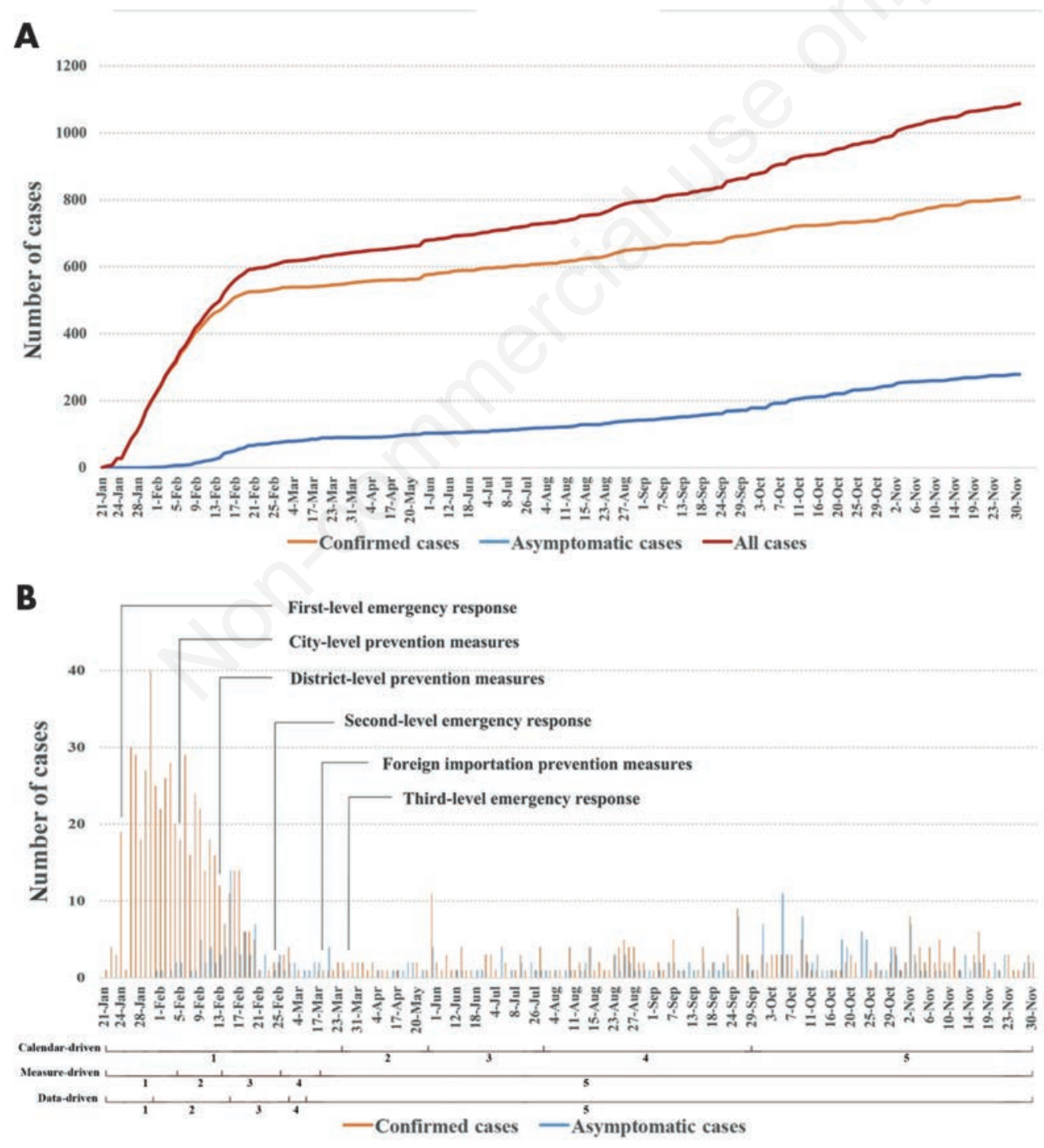

Figure 1. The number of confirmed and asymptomatic COVID-19 cases in Sichuan, China in 2020. A) Aggregated numbers; B) daily numbers. 


\section{Materials and methods}

\section{Study site}

Sichuan, a central-western Chinese province, consists of 21 city-level administrative units (18 cities and 3 autonomous prefectures) and has the fourth largest population in China (90.99 million by the end of 2019). The first case of COVID-19 was confirmed in Sichuan on $21^{\text {st }}$ January 2020. The epidemic has been waning in Sichuan as only cases imported into China from foreign countries have been detected since $22^{\text {nd }}$ June 2020 . This has made Sichuan a suitable study area for our purpose of understanding the COVID19 epidemic course.

\section{Data collection}

Information on the individual COVID-19 cases during $21^{\text {st }}$ January to $30^{\text {th }}$ November 2020 in Sichuan, both confirmed and asymptomatic (i.e. those without self-perceived or clinically identified symptoms such as fever, cough and sore throat, yet test positive), was obtained from the Health Commission of Sichuan Province and field surveys that included gender, age, date of onset, date of diagnosis, place of reporting, clinical severity and source of infection. All cases tested positive for COVID-19 when diagnosed by clinical experts according to the Covid-19 treatment plan (Trial version 7) released by the National Health Commission of the People's Republic of China (2020a). The clinical severity of the confirmed COVID-19 cases was classified into critical, moderate and mild cases: critical cases had respiratory failure, septic shock or multiple organ dysfunction failure; moderate cases had fever, respiratory tract symptoms and image manifestations of pneumonia; and mild cases presented mild symptoms without fever or image manifestations of pneumonia (National Health Commission of the People's Republic of China, 2020a; Yu et al., 2020). The asymptomatic cases were reported according to the COVID-19 prevention and control plan (6th edition) (National Health Commission of the People's Republic of China, 2020b). The sources of infection included importation from Hubei, importation from other Chinese provinces, local infections, imported cases from foreign countries, and uncertain.

\section{The epidemic course}

We used three methods, both subjective and objective, to divide the epidemic course. A calendar-based method divides the epidemic course evenly into five periods: $21^{\text {st }}$ January to $23^{\text {rd }}$ March $(\mathrm{C} 1) ; 24^{\text {th }}$ March to $25^{\text {th }}$ May $(\mathrm{C} 2) ; 26^{\text {th }}$ May to $27^{\text {th }}$ July (C3); $28^{\text {th }}$ July to $28^{\text {th }}$ September $(\mathrm{C} 4)$; and $29^{\text {th }}$ September to $30^{\text {th }}$

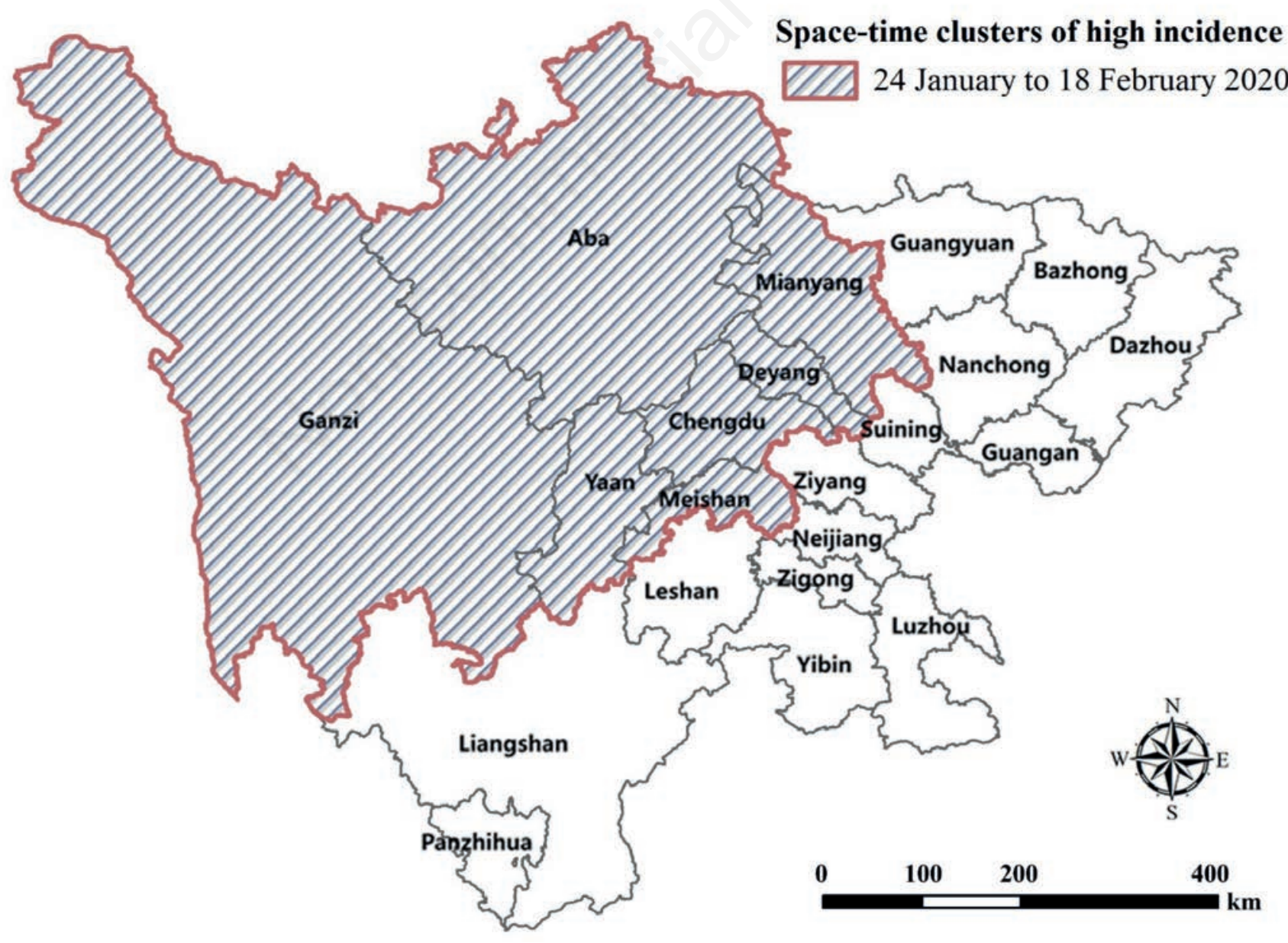

Figure 2. Spatiotemporal clustering patterns of the city-level incidence of COVID-19 in Sichuan, China. 
November 2020 (C5). A measure-driven method divides the epidemic course on the basis of the implementation of different types and levels of emergency response and prevention measures into five different periods: M1) $21^{\text {st }}$ January to $4^{\text {th }}$ February, during which the first-level emergency response (implementing strict quarantine measures) came into force on $24^{\text {th }}$ January; M2) $5^{\text {th }}$ to $12^{\text {th }}$ February, in which city-level prevention measures were implemented by classifying all cities into areas with local outbreaks, sporadic cases and no cases; M3) $13^{\text {th }}$ to $25^{\text {th }}$ February, in which district-level prevention measures were implemented by the same classification (local outbreaks, sporadic cases and no cases) for fine-scale prevention measures; M4) $26^{\text {th }}$ February to $17^{\text {th }}$ March, in which the second-level emergency response took effect by suggesting people to reduce the frequency of going out and visiting crowded places; and M5) $18^{\text {th }}$ March to $30^{\text {th }}$ November, in which quarantining and conducting polymerase chain reaction (PCR) tests for travellers/visitors from overseas were implemented. The third-level emergency response (i.e. resuming normal life with caution regarding potential importation of COVID-19 from overseas and local resurgences) also took effect on $25^{\text {th }}$ March. Such divisions could reveal the effectiveness of a given measure by comparing the distribution patterns before and after its implementation. A data-driven method divided the epidemic course into five periods on the basis of landmark changes in the temporal trend of COVID-19 cases, such as increasing, peaking, lowering, disappearance and resurgence.

\section{Data analyses}

The epidemiological characteristics of the COVID-19 cases (overall and by period) and the temporal trends of the daily numbers of new cases (overall, confirmed and asymptomatic) were analysed. All individual COVID-19 cases were geocoded and aggregated by city in which they resided at present, which was also where they were confirmed (symptomatic) or detected (asymptomatic). The space-time scan statistics, using discrete Poisson models, were conducted at the city level on a daily basis to identify spatial clustering patterns of high COVID-19 incidence, which have also remained over time (Kulldorff et al., 1998). Local Moran's I (Anselin, 2010), another type of spatial clustering analysis, was employed to scrutinize the degree and scope of spatial clustering of the aggregated cases and the average daily incidence of COVID-19 across periods among cities. This approach shows five types of spatial clustering patterns: high number(s) surrounded by high numbers $(\mathrm{HH})$, low number(s) surrounded by low numbers (LL), a high number surrounded by low numbers (HL), a low num-

Table 1. Characteristics of the COVID-19 cases in Sichuan of China within the data-driven epidemic periods.

\begin{tabular}{|c|c|c|c|c|c|c|c|}
\hline \multirow[t]{2}{*}{ Variable } & \multirow[b]{2}{*}{ All } & \multicolumn{5}{|c|}{$N(\%)$ - confirmed $(n=808)$} & \multirow[t]{2}{*}{ Asymptomatic $(\mathrm{n}=279)$} \\
\hline & & D1 $(n=172)$ & D2 $(n=308)$ & D3 $(n=58)$ & D4 $(n=1)$ & D5 $(n=269)$ & \\
\hline $\begin{array}{c}\text { Age group } \\
0-19 \\
20-29 \\
30-39 \\
40-49 \\
50-59 \\
60-69 \\
70-79 \\
>80\end{array}$ & $\begin{array}{c}46(5.7) \\
135(16.7) \\
194(24.0) \\
200(24.8) \\
138(17.1) \\
62(7.7) \\
24(3.0) \\
9(1.1)\end{array}$ & $\begin{array}{c}6(3.5) \\
28(16.3) \\
53(30.8) \\
42(24.4) \\
21(12.2) \\
18(10.5) \\
2(1.2) \\
2(1.2)\end{array}$ & $\begin{array}{l}24(7.8) \\
36(11.7) \\
56(18.2) \\
81(26.3) \\
58(18.8) \\
29(9.4) \\
18(5.8) \\
6(1.9)\end{array}$ & $\begin{array}{c}4(6.9) \\
7(12.1) \\
9(15.5) \\
9(15.5) \\
18(31.0) \\
7(12.1) \\
3(5.2) \\
1(1.7)\end{array}$ & $\begin{array}{c}0 \\
0 \\
1(100) \\
0 \\
0 \\
0 \\
0 \\
0\end{array}$ & $\begin{array}{c}12(4.5) \\
64(23.8) \\
75(27.9) \\
68(25.3) \\
41(15.2) \\
8(3.0) \\
1(0.4) \\
0\end{array}$ & $\begin{array}{l}33(11.8) \\
84(30.1) \\
80(28.7) \\
47(16.8) \\
25(9.0) \\
6(2.2) \\
2(0.7) \\
2(0.7)\end{array}$ \\
\hline $\begin{array}{ll}\text { Sex } & \\
& \text { Male } \\
& \text { Female } \\
\end{array}$ & $\begin{array}{l}517(64.0) \\
291(36.0)\end{array}$ & $\begin{array}{l}98(57.0) \\
74(43.0)\end{array}$ & $\begin{array}{l}157(51.0) \\
151(49.0)\end{array}$ & $\begin{array}{l}30(51.7) \\
28(48.3)\end{array}$ & $\begin{array}{c}0 \\
1(100)\end{array}$ & $\begin{array}{c}232(86.2) \\
37(13.8)\end{array}$ & $\begin{array}{c}197(70.6) \\
82(29.4)\end{array}$ \\
\hline $\begin{array}{l}\text { Clinical severity } \\
\text { Critical } \\
\text { Moderate } \\
\text { Mild }\end{array}$ & $\begin{array}{c}3(0.4) \\
547(67.7) \\
258(31.9)\end{array}$ & $\begin{array}{c}1(0.6) \\
104(60.5) \\
67(39.0)\end{array}$ & $\begin{array}{c}2(0.6) \\
181(58.8) \\
125(40.6)\end{array}$ & $\begin{array}{c}0 \\
47(81.0) \\
11(19.0)\end{array}$ & $\begin{array}{c}0 \\
1(100) \\
0\end{array}$ & $\begin{array}{c}0 \\
214(79.6) \\
55(20.4)\end{array}$ & $\begin{array}{l}- \\
- \\
-\end{array}$ \\
\hline $\begin{array}{l}\text { Occupation } \\
\text { Service worker } \\
\text { Public official } \\
\text { Healthcare worker } \\
\text { Home worker } \\
\text { Farmer } \\
\text { Migrant worker } \\
\text { Student/Child } \\
\text { Others }\end{array}$ & $\begin{array}{l}119(14.7) \\
82(10.1) \\
10(1.2) \\
132(16.3) \\
155(19.2) \\
159(19.7) \\
73(9.0) \\
78(9.7)\end{array}$ & $\begin{array}{c}38(22.1) \\
29(16.9) \\
4(2.3) \\
30(17.4) \\
24(14.0) \\
22(12.8) \\
12(7.0) \\
13(7.6)\end{array}$ & $\begin{array}{l}30(9.7) \\
32(10.4) \\
6(1.9) \\
65(21.1) \\
87(28.2) \\
24(7.8) \\
26(8.4) \\
38(12.3)\end{array}$ & $\begin{array}{c}2(3.4) \\
1(1.7) \\
0 \\
5(8.6) \\
41(70.7) \\
3(5.2) \\
2(3.4) \\
4(6.9)\end{array}$ & $\begin{array}{c}0 \\
0 \\
0 \\
0 \\
1(100) \\
0 \\
0 \\
0\end{array}$ & $\begin{array}{c}49(18.2) \\
20(7.4) \\
0 \\
32(11.9) \\
2(0.7) \\
110(40.9) \\
33(12.3) \\
23(8.6)\end{array}$ & $\begin{array}{c}64(22.9) \\
22(7.9) \\
0 \\
38(13.6) \\
27(9.7) \\
73(26.2) \\
44(15.8) \\
11(3.9)\end{array}$ \\
\hline $\begin{array}{l}\text { Source of infection } \\
\text { From Hubei } \\
\text { From other provinces } \\
\text { Local infection } \\
\text { From overseas } \\
\text { Uncertain sources }\end{array}$ & $\begin{array}{l}235(29.1) \\
81(10.2) \\
140(17.3) \\
267(33.0) \\
85(10.5)\end{array}$ & $\begin{array}{c}135(78.5) \\
17(9.9) \\
18(10.5) \\
0 \\
2(1.2)\end{array}$ & $\begin{array}{c}96(31.2) \\
57(18.5) \\
100(32.5) \\
0 \\
55(17.9)\end{array}$ & $\begin{array}{c}3(5.2) \\
5(8.6) \\
22(37.9) \\
0 \\
28(48.3)\end{array}$ & $\begin{array}{c}0 \\
1(100) \\
0 \\
0 \\
0\end{array}$ & $\begin{array}{c}1(0.3) \\
1(0.3) \\
0 \\
267(99.3) \\
0\end{array}$ & $\begin{array}{c}0 \\
0 \\
0 \\
0 \\
279(100)\end{array}$ \\
\hline
\end{tabular}

D1, $21^{\text {st }}$ to $30^{\text {th }}$ January; D2, 31 $1^{\text {st }}$ January to $15^{\text {th }}$ February; D3, $16^{\text {th }}$ to $29^{\text {th }}$ February; D4, $1^{\text {st }}$ to $12 t^{\text {th }}$ March; D5, $13^{\text {th }}$ March to $30^{\text {th }}$ November. 
ber surrounded by high numbers (LH) and no spatial clustering (randomness). Note that, to be more comparable across cities with different population densities, the incidence of COVID-19 in each city (daily or within a given period) was calculated as the number of cases per 10 million population as given at the end of 2019 .

Descriptive statistics, space-time scan statistics and spatial clustering analysis and visualization were conducted in RStudio, version 1.3.1093 (https://www.rstudio.com/), SaTScan, version 9.6 (https://www.satscan.org/), and ArcGIS, version 10.3 (ESRI, Redlands, CA, USA), respectively.

\section{Results}

\section{Epidemiological characteristics}

The ages of 808 confirmed COVID-19 cases ranged from 1 month to 87 years, with a median age of 42 years (Table 1). About $64.0 \%$ of those cases were males, and $29.1 \%$ were imported from Hubei. In terms of clinical severity, most $(67.7 \%)$ were moderate cases, followed by mild $(31.9 \%)$ and critical cases $(0.4 \%)$. The largest percentage of cases among the occupations was migrant workers followed by farmers, home workers and service workers. Most confirmed cases were reported during $21^{\text {st }}$ January and $17^{\text {th }}$ February in a dramatic increase (Figure 1A), with the daily number of new cases gradually increasing to 40 on $30^{\text {th }}$ January and remaining at this level until $17^{\text {th }}$ February (Figure 1B). After that, the number of new infections trended lower.

The 279 asymptomatic cases were from 8 months to 81 years old and had a median age of 31 years (Table 1). About $70.6 \%$ of the patients were males and the largest percentage of the asymptomatic cases consisted of migrant workers $(26.2 \%)$ followed by service workers $(22.9 \%)$. The epidemic pattern of the asymptomatic cases was different from that of the confirmed ones, with the first asymptomatic case reported 10 days later than the first confirmed one (Figure 1A). The asymptomatic cases increased rapidly during February although at a smaller scale than that of the confirmed ones.

A high-incidence COVID-19 cluster was detected covering the centre of the province, including Chengdu and the surrounding cities Deyang, Mianyang, Yaan and Meishan and the north-western regions of Sichuan (Ganzi and $\mathrm{Aba}$ ), which remained significant $(\mathrm{P}<0.001)$ from $24^{\text {th }}$ January to $18^{\text {th }}$ February 2020 (Figure 2 ).

\section{The calendar-based division}

During $21^{\text {st }}$ January to $23^{\text {rd }}$ March (C1), the total COVID-19 case number in Chengdu was 162, which was higher than in any of the other 20 cities (Figure 3). The pandemic then entered a stable stage in the province with a mean daily incidence of $0.05,0.10$, 0.25 and 0.39 cases $/ 10$ million during $24^{\text {th }}$ March to $25^{\text {th }}$ May (C2), $26^{\text {th }}$ May to $27^{\text {th }}$ July (C3), $28^{\text {th }}$ July to $28^{\text {th }}$ September (C4) and $29^{\text {th }}$ September to $30^{\text {th }}$ November (C5), respectively (Table 2).

\section{The measure-driven division}

The epidemic course was divided into five periods, according to different types and levels of emergence response and prevention measures taken in Sichuan (Figure 1B). In the middle of the M1 period (before the city-level prevention measures were implemented), the number of new confirmed cases peaked (on $30^{\text {th }}$ January) after which the growth rate started to slow down, which seemed to be attributed to the strict quarantine measures of the first-level emergency response implemented three days after confirming the first case. A continuing downward trend of new confirmed cases was observed during the M2 period when the city-level prevention measures were being implemented, and this trend continued during the M3 period when the district-level prevention measures were being implemented. The M4 period (i.e. when the second-level emergency response was implemented) was a stable stage, with 20 new cases reported over 21 days. In the M5 period, the government focused on preventing the imported COVID-19 cases from foreign countries, as the first overseas case was reported on $13^{\text {th }}$ March, with a total of 462 cases during that period (about 1.79 cases per day). Travellers arriving in Sichuan from overseas during the M5 period were quarantined for two weeks and several received PCR tests during their quarantine.

The average daily incidence was highest in the M2 period (2.39 cases/10 million), followed by the M1 (2.18 cases/10 million) and M3 (1.12 cases/10 million) periods (Table 2). Also, there were strong spatial heterogeneities in the average daily incidence,

Table 2. New cases and the average daily incidence of COVID-19 in Sichuan, China as measured by the three division approaches.

\begin{tabular}{|c|c|c|c|c|c|}
\hline \multirow[t]{2}{*}{ Division } & \multicolumn{5}{|c|}{ Epidemic course periods (duration) } \\
\hline & $\begin{array}{c}\text { 01/21-03/23 } \\
\text { (63 days) }\end{array}$ & $\begin{array}{c}\text { 03/24-05/25 } \\
\text { (63 days) }\end{array}$ & $\begin{array}{c}\text { 05/26-07/27 } \\
\text { (63 days) }\end{array}$ & $\begin{array}{c}\text { 07/28-09/28 } \\
\text { (63 days) }\end{array}$ & $\begin{array}{c}\text { 09/29-11/30 } \\
\text { (63 days) }\end{array}$ \\
\hline \multicolumn{6}{|l|}{ Calendar-based } \\
\hline Number of new cases & 634 & 29 & 58 & 141 & 225 \\
\hline Accumulated number of cases & 634 & 663 & 721 & 862 & 1087 \\
\hline Average daily incidence & 1.11 & 0.05 & 0.10 & 0.25 & 0.39 \\
\hline \multirow[t]{2}{*}{ Measure-driven } & 01/21-02/04 & 02/05-02/12 & 02/13-02/25 & 02/26-03/17 & $03 / 18-11 / 30$ \\
\hline & (15 days) & (8 days) & (13 days) & (21 days) & (258 days) \\
\hline Number of new cases & 298 & 174 & 133 & 20 & 462 \\
\hline Accumulated number of cases & 298 & 472 & 605 & 625 & 1,087 \\
\hline Average daily incidence & 2.18 & 2.39 & 1.12 & 0.10 & 0.20 \\
\hline \multirow[t]{2}{*}{ Data-driven } & $01 / 21-01 / 30$ & $01 / 31-02 / 15$ & $02 / 16-02 / 29$ & 03/01-03/12 & 03/13-11/30 \\
\hline & (10 days) & (16 days) & (14 days) & (12 days) & (263 days) \\
\hline Number of new cases & 172 & 351 & 94 & 1 & 469 \\
\hline Accumulated number of cases & 172 & 523 & 617 & 618 & 1087 \\
\hline Average daily incidence & 1.89 & 2.41 & 0.74 & 0.01 & 0.20 \\
\hline
\end{tabular}

The case numbers are counted per 10 million population within the five epidemic periods. 
with high-risk cities changing ranking places over the five periods (Figure 4). With 92 aggregated cases, Chengdu had the highest number of cases during the M1 period (Figure 5); Ganzi was the city with the highest average daily incidence of 7.22 cases/10 million. During the M2 period, the intensity of COVID-19 in Ganzi ( 7.22 to 26.04 cases/10 million) and Dazhou (1.98 to 5.03 cases/10 million) increased observably, while the average daily incidence of Panzhihua decreased dramatically (5.91 to 2.02 cases/10 million). Most of the cities in Sichuan saw a slowdown during the M3 period, while the opposite happened in Ganzi, with an average daily incidence of 33.97 cases/10 million, which was 7.93 higher than in the M2 period. During the M4 period, 12 cities of Sichuan had no new case, while Ganzi reported seven ones, which was the highest in Sichuan so far. Compared with the M4 period, there was a rebound in some cities during the M5 period due to importation of COVID-19 from foreign countries, especially in Chengdu with 451 cases arriving from overseas.

\section{The data-driven division}

According to the varying trends of COVID-19 cases (Figure 1B), the epidemic course was divided into five periods. During $21^{\text {st }}$ to $30^{\text {th }}$ January (D1), the number of new confirmed cases grew rapidly, most of them imported from Hubei (Table 1). During $31^{\text {st }}$ January to $15^{\text {th }}$ February (D2), the number of new confirmed cases rose at a lower increasing rate, with decreasing numbers of cases from Hubei and increasing local infections; also, asymptomatic cases started to be reported at this time. Local infection became the main source of infection during $16^{\text {th }}$ to $29^{\text {th }}$ February (D3), with the growth rate of new asymptomatic cases peaking on $15^{\text {th }}$ February and then gradually declining. The period of $1^{\text {st }}$ to $12^{\text {th }}$ March (D4) was a stable stage, with only 1 case over 12 days. Imported cases from foreign countries started to emerge on $13^{\text {th }}$ March and lasted till $30^{\text {th }}$ November (D5), with a total of 460 cases over 263 days (1.75 cases per day on average).
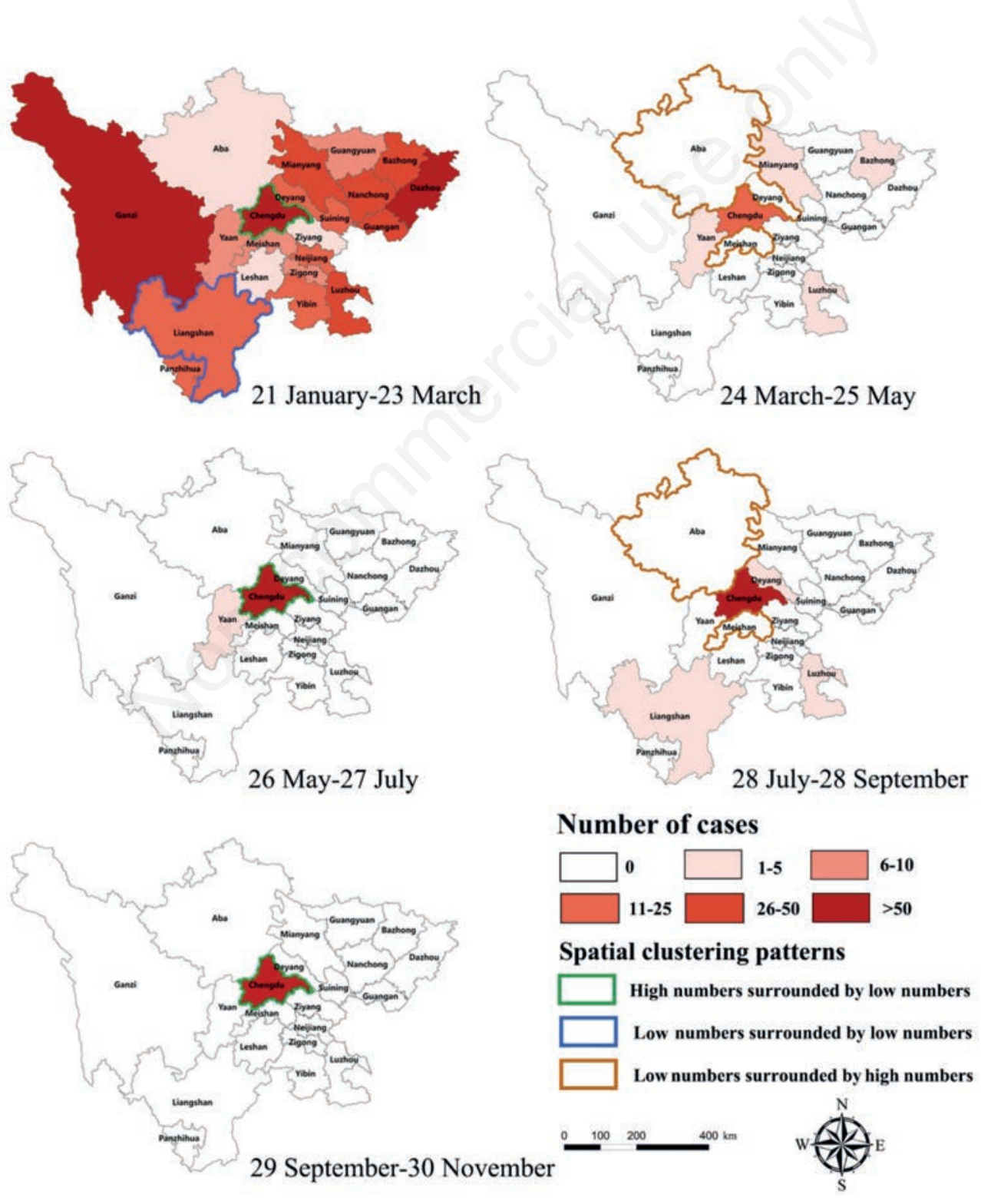

Number of cases

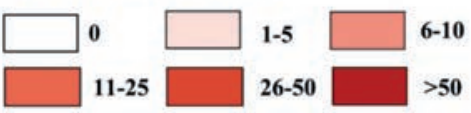

\section{Spatial clustering patterns}

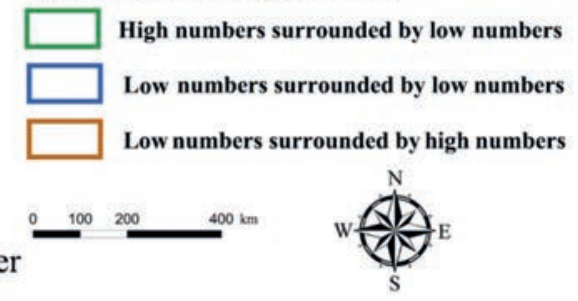

Figure 3. Numbers of the aggregated COVID-19 cases in Sichuan of China within five calendar-based epidemic periods. 
The epidemiological characteristics of the confirmed cases varied across the five periods (Table 1). The mean age of the majority of the confirmed cases had increased before the stable period, and it decreased due to younger cases during the D5 period. The percentage of clinically moderate cases was larger than that of critical and mild cases during all periods, and critical cases disappeared completely after the D3 period. Among the occupations, farmers comprised the largest percentage of confirmed cases during most periods, except at the beginning of the epidemic (D1) when service workers overtook them in this respect together with migrant workers during the D5 period. Countries from which large percentages of the cases had been imported to Sichuan included Egypt (71 cases), followed by Philippines (69), Iraq (53), Pakistan (34), Nepal (31), Ethiopia (29), Singapore (23), Nigeria (22), Saudi Arabia (17), the UK (15), the US (13) and Qatar (12).

The average daily incidence was highest in the D2 period (2.41 cases/10 million), followed by the D1 (1.89 cases/10 million) and
D3 (0.74 cases/10 million) periods. Compared to cities, such as Beijing, Shanghai and Guangzhou, only a limited number of international flights landed in Sichuan. This made the magnitude of the cases in the D5 period significantly less than in the periods D1-3 (Table 2). Also, there were strong spatial heterogeneities in the average daily incidence, with high-risk places changing ranking places in this respect over all the periods (Figure 6): until $30^{\text {th }}$ January, the number of total cases in Chengdu was 64, which was the highest of Sichuan (Figure 7); each of the other cities had less than 20 cases during the D1 period. During the D2 period, the number of aggregated new cases in Chengdu was 81 , which was still the highest in the province, but the average daily incidence decreased slightly (3.92 to 3.10 cases/10 million). The intensity of COVID-19 in some cities increased apparently during the D2 period, such as Ganzi (4.17 to 29.69 cases/10 million), Panzhihua ( 0.81 to 6.55 cases/10 million) and Dazhou (1.05 to 4.26 cases/10 million). There was a slowdown of the trend in most of the cities
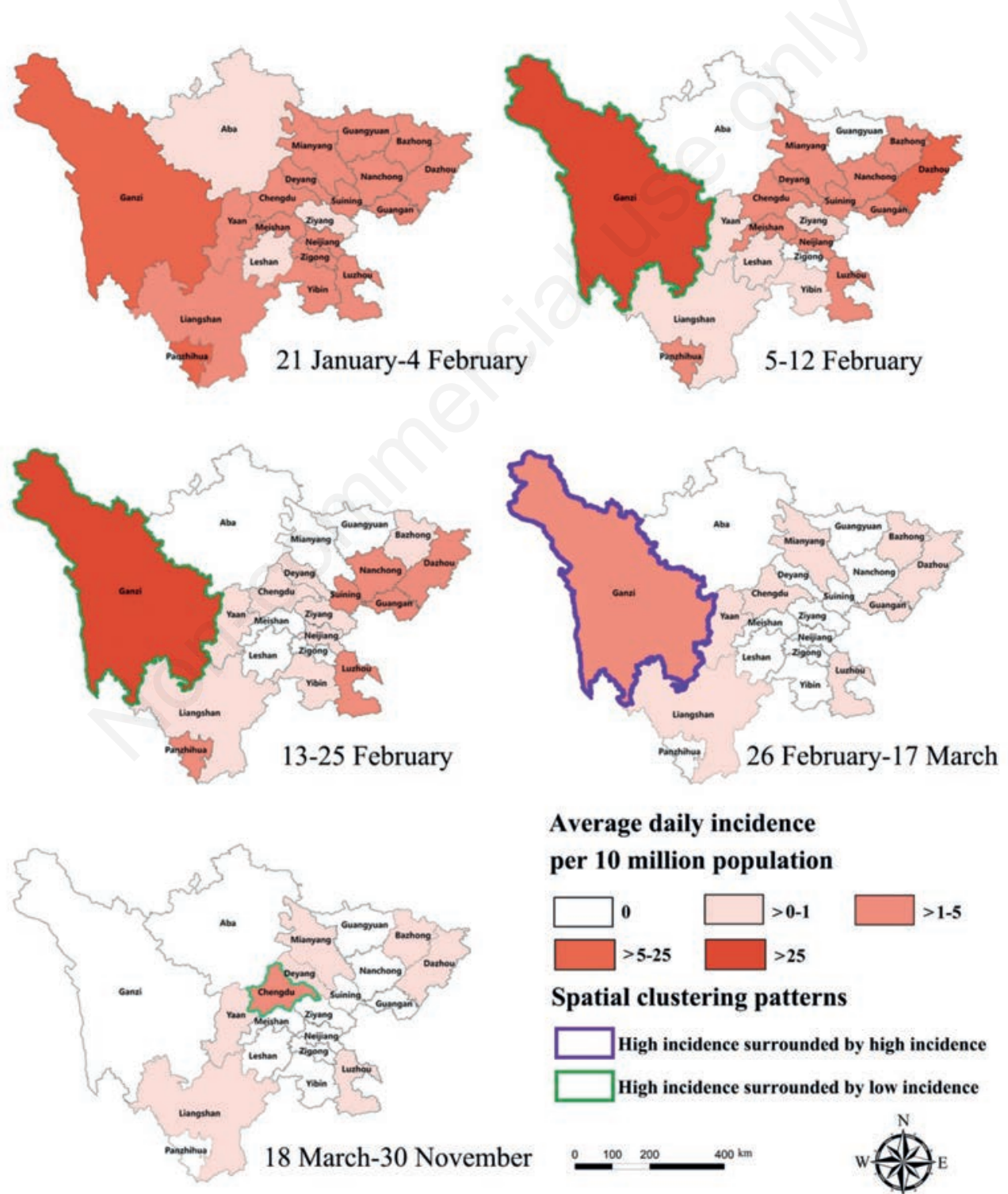

\section{Average daily incidence per 10 million population}

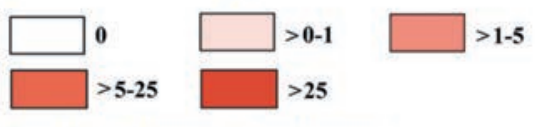

\section{Spatial clustering patterns}

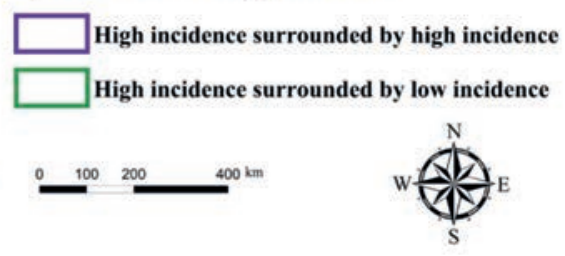

Figure 4. Spatial patterns of the average daily incidence of COVID-19 in Sichuan within the five measure-driven epidemic periods. Unit: number of cases per 10 million population. 
during the D3 period, while the opposite happened in Ganzi that had an average daily incidence of 21.43 cases/10 million. Compared with the D4 period, which was a stable period, there was a rebound in some cities during the D5 period due to importation from foreign countries, especially in Chengdu with an average daily incidence of 1.06 cases/10 million.

\section{Discussion}

This first, spatial epidemic course analysis on the basis of individual COVID-19 cases in Sichuan Province of China includes an epidemiological analysis of the distribution and transmission of the disease. Compared with other studies (Wang et al., 2020; Yu et al., 2020), our study period was more complete covering all main stages of COVID-19 in our study area. The confirmed cases were generally older prior to the final period of infected travellers from foreign countries, where the majority of the cases were younger. The main sources of infection changed from the initial importation from Hubei to importation from other provinces, then to local infection and ultimately to imported cases from foreign countries. The clinical symptoms of the COVID-19 cases have become less severe over time. The largest proportion consisted of cases involving migrant workers, both confirmed and asymptomatic, and particularly cases arriving from foreign countries.

We implemented the three different approaches to divide the epidemic course of COVID-19 in Sichuan into five separate periods, with spatiotemporal epidemic patterns presented in each period under each approach. The epidemic trends of COVID-19 by period varied by approaches (i.e. time windows) selected for dividing the epidemic course: the calendar-based periods were even, so dynamic transmission patterns of COVID-19 due to various sources of infection were neither considered nor hence reflected,
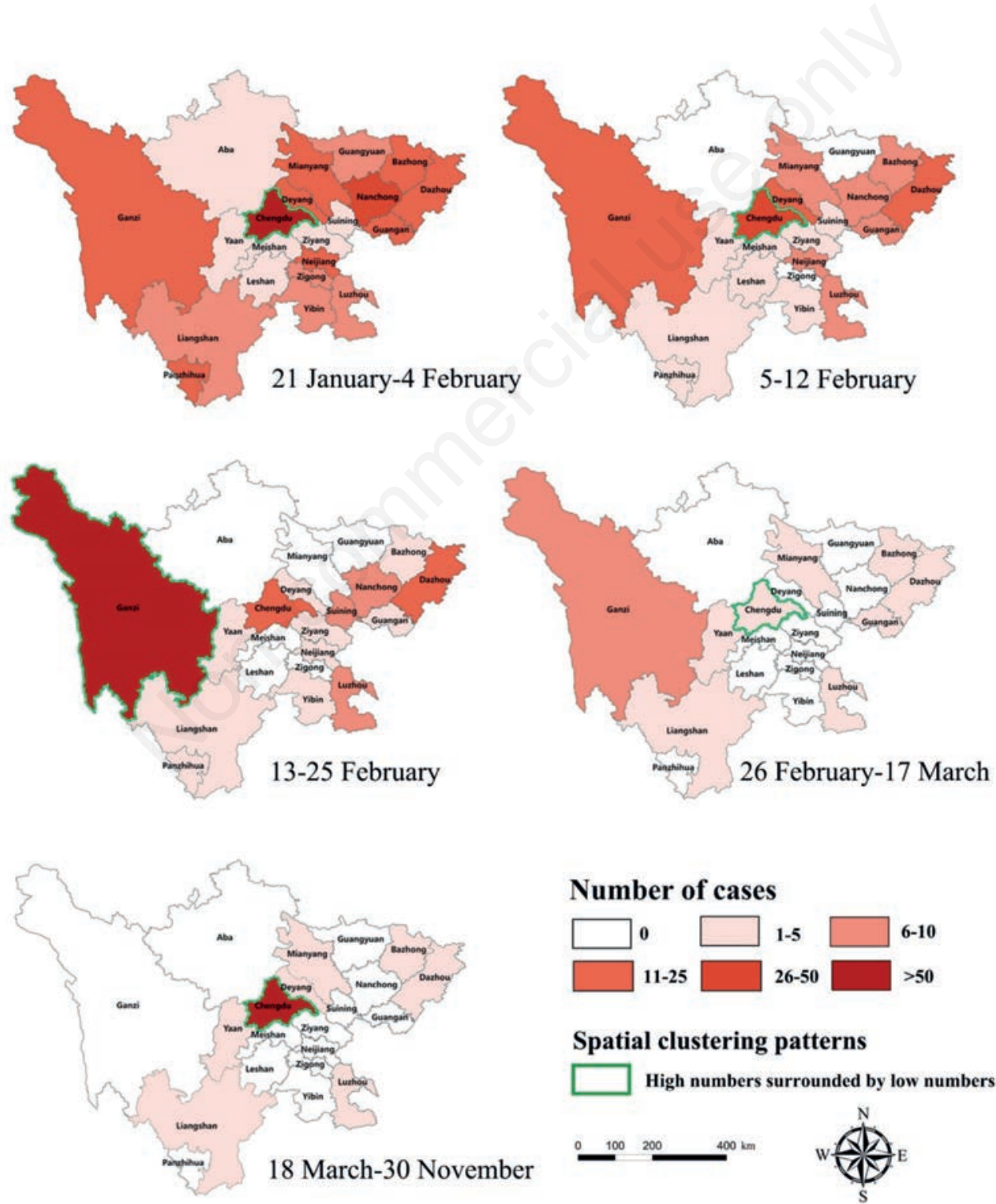

\section{Number of cases}

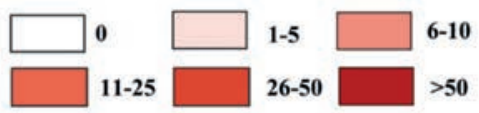

\section{Spatial clustering patterns}

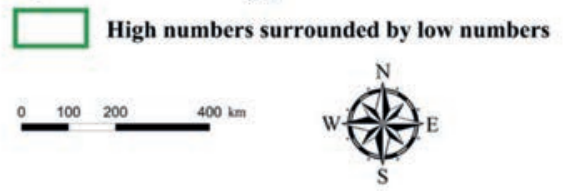

Figure 5. Numbers of the aggregated COVID-19 cases in Sichuan of China within five measure-driven epidemic periods. 
with most cases aggregated in the first period (M1), while the measure-driven and data-driven approaches resulted in a temporal lag between the periods.

There was a time lag observed between the implementation of prevention measures and the change in the epidemic trend. The most abrupt decrease in the number of new confirmed cases (start of D2) was seven days later than the beginning of the first-level emergency response (during M1). The steepest decline in the number of new asymptomatic cases (start of D3) occurred three days after the implementation of the district-level prevention measures (start of M3). The stable period (D4) started four days after downgrading the first-level emergency response to the second-level (start of M4). Such temporal lags visualize the influence of the first-level emergency response and city/district-level prevention measures on COVID-19 transmission, here showing a clear reduction. There were also apparent differences in the spatial patterns of the COVID-19 incidence between each pair of periods from the two methodological approaches. The greatest differences were seen during the $4^{\text {th }}$ periods, with new cases in nine cities during M4 and only one case in Chengdu during D4. These disparities show a better alignment of the data-driven periods with the real-world epidemic trends.

We compared the measure-driven and data-driven periods to better understand the time lag between the implementation and effects of the measures, in order to forecast more accurately the effects of implementing prevention measures on epidemic trends in future epidemics. A study in the U.S. has also revealed a time lag of 1-5 weeks before seeing a decreased growth rate of the confirmed cases by implementing the containment measures (e.g., stay-at-home orders, workplace closures and public information campaigns) (Li et al., 2021). The change in epidemic trends from one stage to another may vary by the time windows selected for the
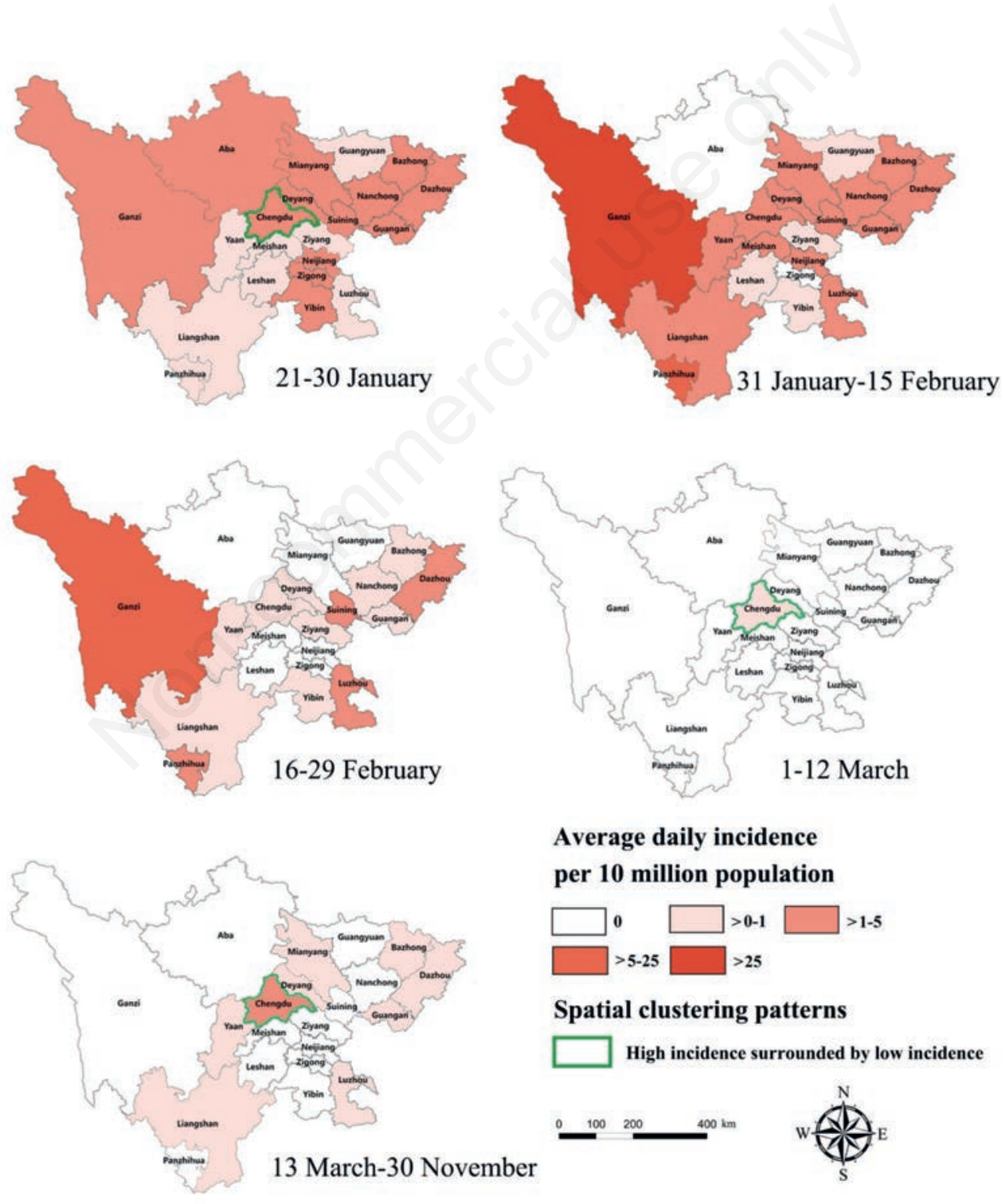

\section{Average daily incidence per 10 million population}

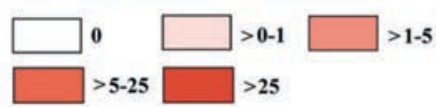

\section{Spatial clustering patterns}

High incidence surrounded by low incidence
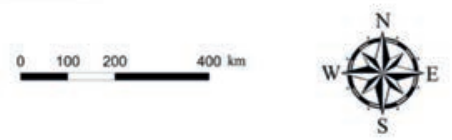

Figure 6. Spatial patterns of the average daily incidence of COVID-19 in Sichuan within the five data-driven epidemic periods. Unit: number of cases per 10 million population. 
stages in the analyses, something which is referred to as the modifiable temporal unit problem (MTUP) (Tao et al., 2014). Results from a single approach-based division of a given epidemic period are usually subject to MTUPs. Due to the time lag between implementation and effects of counteractive measures against COVID19 , this type of arbitrary outcomes has impeded an adequate understanding of its epidemic course and obstructed accurate assessments of the value of early-stage measures. To overcome these conceptual problems and methodological limitations, there is a need for the application of multiple approaches dividing the epidemic course, so that different results can be compared and combined to achieve a more predictable and MTUP-free epidemic trend. Indeed, this approach would also be generalizable.

At late stages of COVID-19, imported cases from foreign countries constitute the main source of infection. When only adopting the measure-driven division approach, it was difficult to demonstrate the severity of importation from overseas, which, unlike importation from Hubei and local transmission, is affected by the global pandemic situation and preventive measures implemented by origin countries and international airlines. Therefore, the effect of measures preventing infection via imported cases could not be evaluated only by counting the number of new cases. In the beginning of the M5 period, measures aimed at preventing foreign influx of COVID-19 were implemented by the Sichuan government. From $20^{\text {th }}$ March 2020, all people entering Sichuan from overseas were collectively quarantined and subjected to PCR testing, a measure effectively precluding further local transmission.

The entire epidemic course of COVID-19 was over in Sichuan already in late 2020, which was earlier than most regions, and definitely compared to other countries. This is mainly attributed to the implementation of a region-specific, multi-level approach at the
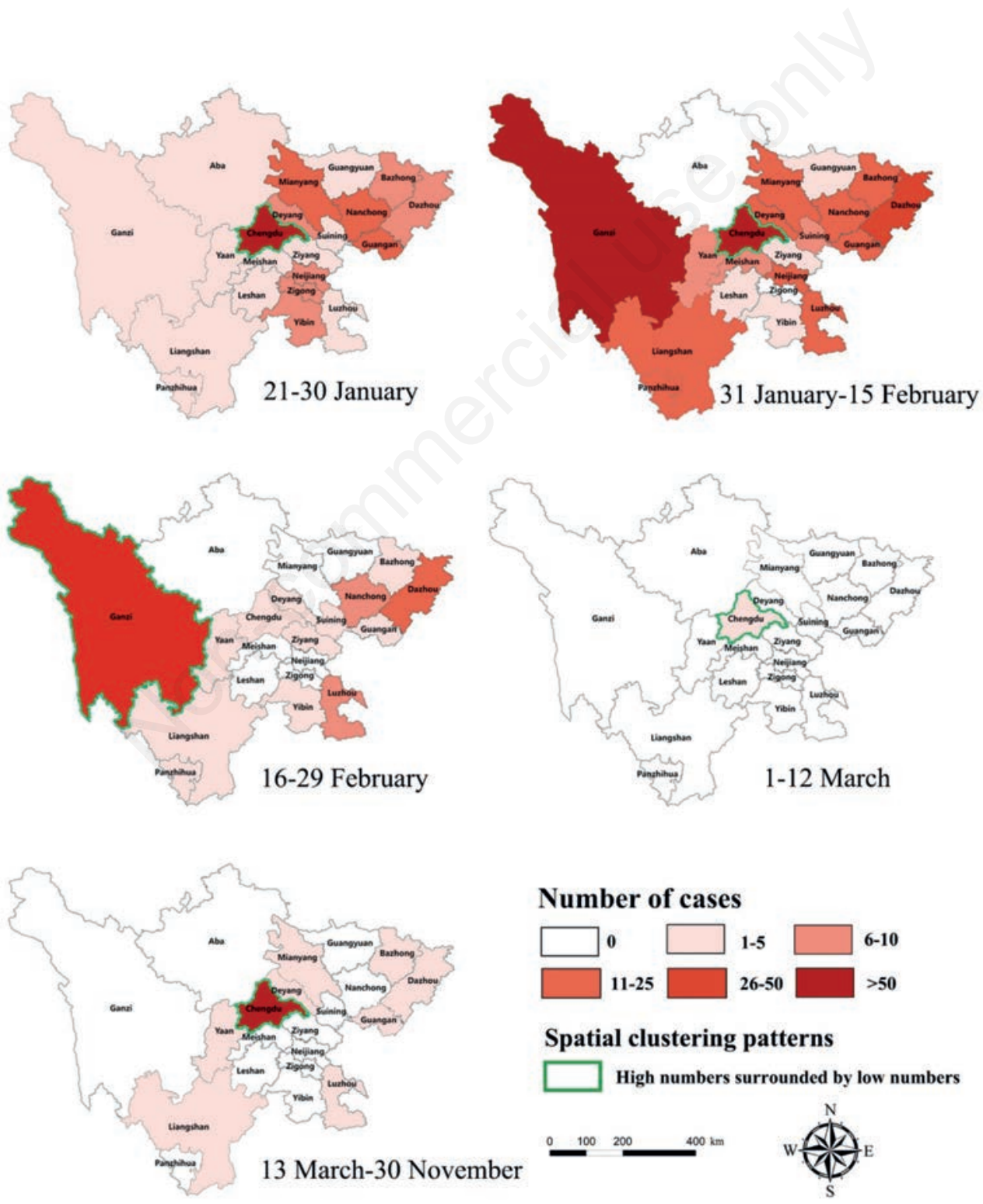

\section{Number of cases}

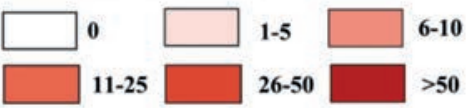

\section{Spatial clustering patterns}

High numbers surrounded by low numbers
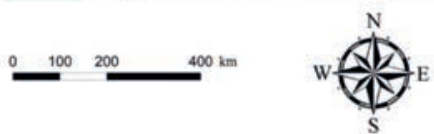

Figure 7. Numbers of the aggregated COVID-19 cases in Sichuan of China within five data-driven epidemic periods. 
early stage of the pandemic. In the beginning of February 2020, the region-specific and sector-specific COVID-19 control strategies were proposed at the national level, promptly followed in Sichuan by adapting and tailoring the national strategies to the local situation and issuing detailed regulations within 10 days. In midFebruary 2020, all districts/counties (an administrative resolution below the city level) in China were divided into three classes with different levels of risk (low, moderate and high). This was adopted in Sichuan immediately (after three days) by dividing districts/counties one step further into sub-districts/towns and introducing four local classes with different levels of risk, with consideration of both epidemic prevention at the broad scale and convenience of local residents in their daily life, an approach not recommended at the national level until late February 2020. All these factors have greatly contributed to the success of local epidemic control; thus it is extremely important to adapt national strategies and guidelines to local contexts without the slightest delay. Last but not least, Sichuan's success would not be possible without the support and strong popular cooperation.

There were several limitations in this study. First, we could not evaluate the effects of individual measures because, in addition to the main prevention measures, the Sichuan government implemented multiple interventions in the same period to control the epidemic. Second, we referred to the date of diagnosis, instead of the date of onset, to calculate the number of cases, which may to some extent account for the time lag between the implementation and effects of the preventive measures (Wang et al., 2020). However, this has been a common limitation of most, if not all, COVID-19 epidemiological studies. Third, there was a considerable percentage of COVID-19 cases arising from uncertain sources, especially for asymptomatic cases, which, once revealed, may affect the current results (Yang et al., 2021).

\section{Conclusions}

The control and prevention measures undertaken by the Sichuan government so far have been effective. The spatiotemporal patterns of COVID-19 in Sichuan varied across the stages of its epidemic course, and the patterns within each period also varied as the disease developed. Covering the whole cycle of the disease made it possible to reveal a reliable and predictable epidemic course. With COVID-19 waning in China, understanding the epidemic course at this time is critical for deep insights into representative transmission patterns. From the results presented here, the world can learn about what will probably occur next in their own COVID-19 timelines and how to be better prepared for the forthcoming stages. Also, the approaches used for the division of the time periods in this study would assist controlling the development of this disease in other Chinese provinces and in other countries, as well as preventing other (re)emerging infectious diseases in the future (Jia and Yang, 2020b).

\section{References}

Anselin L, 2010. Local Indicators of Spatial Association - LISA. Geogr Anal 27:93-115.
CDC, 2020. How COVID-19 Spreads. Available from: https:// www.cdc.gov/coronavirus/2019-ncov/prevent-getting-sick/ how-covid-spreads.html Accessed: 25 June 2020.

Jia P, 2020. Understanding the epidemic course in order to improve epidemic forecasting. Geohealth 4:e2020GH000303.

Jia P, Dong W, Yang S, Zhan Z, Tu L, Lai S, 2020. Spatial lifecourse epidemiology and infectious disease research. Trends Parasitol 36:234-8.

Jia P, Yang S, 2020a. Time to spatialise epidemiology in China. Lancet Global Health 8:e764-5.

Jia P, Yang S, 2020b. Are we ready for a new era of high-impact and high-frequency epidemics?. Nature 580:321.

Kulldorff M, Athas W, Feurer E, Miller B, Key C, 1998. Evaluating cluster alarms: a space-time scan statistic and brain cancer in Los Alamos, New Mexico. Am J Public Health 88:1377-80.

Li H, Li H, Ding Z, Hu Z, Chen F, Wang K, Peng Z, Shen H, 2020. Spatial statistical analysis of coronavirus disease 2019 (covid19) in China. Geospat Health 15:867.

Li Y, Li M, Rice M, Zhang H, Sha D, Li M, Su Y, Yang C, 2021. The impact of policy measures on human mobility, COVID-19 cases, and mortality in the US: a spatiotemporal perspective. Int J Environ Res Public Health 18:996.

Lipsitch M, Swerdlow DL, Finelli L, 2020. Defining the epidemiology of Covid-19 - studies needed. N Engl J Med 382:1194-6.

National Health Commission of the People's Republic of China, 2020a. Covid-19 treatment plan (trial version 7). Available from: http:/www.nhc.gov.cn/xcs/zhengcwj/202003/ 46c929 4a7dfe4cef80dc7f5912eb1989.shtml Accessed: 25 June 2020.

National Health Commission of the People's Republic of China, 2020b. Covid-19 prevention and control plan (6th edition). Available from: http://www.nhc.gov.cn/xcs/zhengcwj/ 202003/ 4856d5b0458141fa9f376853224d41d7.shtml Accessed: 25 June 2020.

Tao C, Monsuru A, Tobias P, 2014. Modifiable temporal unit problem (MTUP) and Its effect on space-time cluster detection. PLos One 9:e100465-.

Wang KW, Gao J, Wang H, Wu XL, Yuan QF, Guo FY, Zhang ZJ, Cheng Y, 2020. Epidemiology of 2019 novel coronavirus in Jiangsu Province, China after wartime control measures: A population-level retrospective study. Travel Med Infect Dis 35:101654.

WHO, 2020. Coronavirus disease (COVID-19) weekly epidemiological update - 1 December, 2020. Available from: https://www.who.int/publications/m/item/weekly-epidemiological-update-1-december-2020 Accessed: 5 December 2020.

Yang S, Dai S, Huang Y, Jia P, 2021. Pitfalls in modeling asymptomatic COVID-19 Infection. Front Public Health 9:593176.

Yang W, Deng M, Li C \& Huang J, 2020. Spatio-temporal patterns of the 2019-nCoV epidemic at the county level in Hubei Province, China. Int J Environ Res Public Health 17:2563.

Yu X, Sun X, Cui P, Pan H, Lin S, Han R, Jiang C, Fang Q, Kong D, Zhu Y, Zheng Y, Gong X, Xiao W, Mao S, Jin B, Wu H, Fu C, 2020. Epidemiological and clinical characteristics of 333 confirmed cases with coronavirus disease 2019 in Shanghai, China. Transbound Emerg Dis 67:1697-707. 